\title{
$\mathrm{MTMD}$ 를 이용한 보의 진동 억제
}

\section{Vibration Suppression of a Cantilever Beam Using MTMD}

\author{
배 재 성 $†$ 황 재 혁*.김 종 혁*.임 재 혁** \\ Jae-Sung Bae, Jai-Hyuk Hwang, Jong-Hyuk Kim and Jae-Hyuk Lim \\ (2011년 5월 13일 접수 ; 2011년 9월 15일 심사완료)
}

Key Words : $\mathrm{MTMD}$ (magnetically tuned mass damper ; 자기동조질량감쇠기), $\mathrm{TMD}$ (tuned mass damper ; 동조 질량감쇠기), $\mathrm{ECD}$ (eddy current damping ; 자기효과 감쇠)

\begin{abstract}
In the present study, TMD(tuned mass damper) with eddy current damping is proposed to suppress the vibration of a cantilever beam effectively. The advantages of TMD are that it is simple and its performance are excellent at any particular frequency. However, TMD may have the low performance at other frequency. To solve this problem and improve its performance, this study applies the eddy current damping to TMD. This TMD with ECD is named as MTMD(magnetically tuned mass damper). MTMD is designed for the vibration suppression of a cantilever beam. The mathematical modeling, simulation, and experiments of the cantilever beam with MTMD are performed. From analytic and experimental results, it can be concluded that the vibration suppression performance of MTMD are excellent.
\end{abstract}

\section{1. 서 론}

진동으로부터 보호되어야 하나 자체적으로는 진동 을 억제시킬 수 없는 시스템에 대해서 수동형 진동제 어 장치인 동조질량감쇠기(TMD, tuned mass damper) 는 추가적인 흡진시스템의 부착만으로도 진동을 효과 적으로 줄일 수 있는 방법이다. $\mathrm{TMD}$ 는 일종의 진동 흡진기로 주 장치에 부가의 질량-스프링 조합의 흡진 시스템을 적용함으로써 주 장치에 가해지는 진동을 흡수하여 일정한 주파수의 정상상태 조화 외란으로부 터 주장치를 보호하기 위한 수단이다 ${ }^{(1)}$.

이러한 $\mathrm{TMD}$ 는 고층의 빌딩이나 대교 등과 같은 진동이 크게 발생할 수 있어서 진동으로부터 보호

† 교신저자; 정회원, 한국항공대학교 항공우주및기계공학과 E-mail : jsbae@kau.ac.kr

Tel : (02)300-0102, Fax : (02)3158-3189

* 정회원, 한국항공대학교 항공우주및기계공학과

** 한국항공우주연구원 위성구조팀
되어야 하는 건축물에 주로 적용되고 있으며, 향후 헬리콥터와 같은 진동에 대해 민감한 항공기의 진 동 억제와 전차의 사격 정확도의 향상을 위한 포신 의 진동 억제에 이르기까지 다양한 분야로의 적용 이 가능할 것으로 예상된다.

반면에 이러한 $\mathrm{TMD}$ 는 Fig. 1에서 나타낸 바와 같 이, 설계 시 고려된 매우 좁은 특정 주파수 범위에서 는 진동을 흡수하는 성능이 뛰어나지만 특정 주파수 범위를 중심으로 그 부근에서의 주파수 범위에서는 진동 흡수 성능이 떨어지며 공진을 발생시킬 수 있 는 문제점을 지니고 있다. 이는 외부 가진주파수의 범위가 설계 시 고려된 특정 주파수 범위 내에서만 가해진다면 순수 질량-스프링의 $\mathrm{TMD}$ 만으로도 충분 히 우수한 진동 흡수 성능을 지니지만, 외부 가진주 파수의 범위가 특정 주파수 범위를 벗어나거나 주구 조물에 추가적인 부품 추가 또는 변형이 발생하였을 경우 주구조물의 고유진동수의 변화로 인해 기존 $\mathrm{TMD}$ 의 진동 흡수 성능이 감소하여 결과적으로 진동 
억제 성능을 저하시킬 수 있음을 의미한다.

이러한 문제는 흡진시스템에 감쇠를 더함으로써 해결할 수 있으며, 감쇠를 더하는 방안으로 이 연구 에서는 자기효과 감쇠(ECD, eddy current damping) 를 고려하였다. $\mathrm{ECD}$ 는 자석과 전도체 간의 상대적 인 운동으로 인해 발생하는 유도전류(eddy current) 에 의해 생성되는 감쇠이다(2 5).

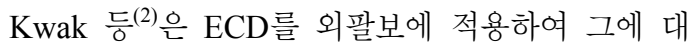
한 효과에 관해 연구를 수행하였으며, 외팔보의 진 동 억제 장치로 $\mathrm{ECD}$ 가 효과가 있음을 보였다. $\mathrm{Bae}$ 등(3)은 $\mathrm{Kwak}$ 등(2)에 의해서 구성된 $\mathrm{ECD}$ 의 이론적 인 모델에 관해 연구하였으며, 이론적인 모델을 사 용하여 $\mathrm{ECD}$ 의 감쇠 특성에 대해 연구하였고 $\mathrm{ECD}$ 를 적용한 외팔보의 진동 억제 해석을 수행하였다. Sodano 등(4,5)은 단순한 영구자석을 이용한 진동억 제 및 전자석을 이용하여 자기장의 변화를 줌으로 써 외팔보의 감쇠 변화를 갖도록 함으로써 피드백 제어를 이용하여 $\mathrm{ECD}$ 를 이용한 외팔보의 진동 억 제에 관한 연구들을 수행하였다.

이 연구에서는 외팔보의 진동을 제어하기 위해 $\mathrm{TMD}$ 를 적용하였으며, $\mathrm{TMD}$ 의 진동흡수성능을 향상 시키고자 $\mathrm{ECD}$ 를 적용하였다. 이 연구에서는 $\mathrm{TMD}$ 와 $\mathrm{ECD}$ 의 결합을 $\mathrm{MTMD}$ (magnetically tuned mass damper)라 명명하였다. 이 연구의 MTMD는 Kwak 등(2)과 Sodano 등(4)이 제안한 방법을 적용이 용이 하게 개선한 것이다. 이 연구에서 제안한 $\mathrm{MTMD}$ 의 성능을 검증하기 위해 우선적으로 외팔보에 대한 $\mathrm{TMD}$ 를 설계하였으며, 그에 대한 실험을 수행하였다.

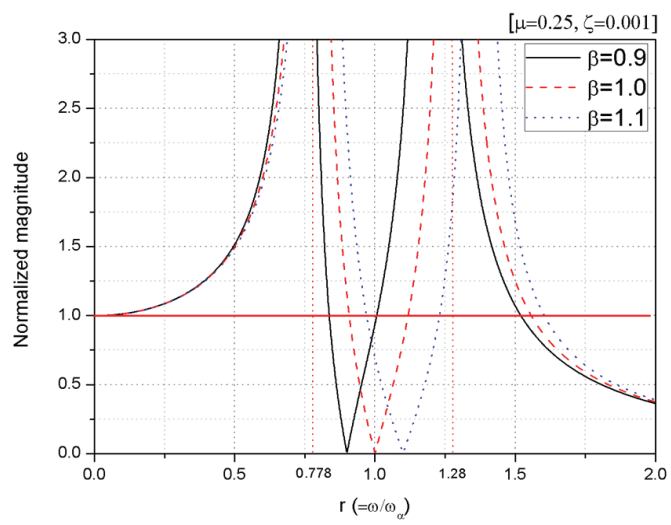

Fig. 1 Normalized magnitude of the primary mass about the normalized driving frequency
$\mathrm{TMD}$ 의 성능을 개선하기 위해 $\mathrm{ECD}$ 를 적용한 $\mathrm{MTMD}$ 를 설계/제작하였으며, 외팔보에 적용함으로 써 향상된 진동흡수성능을 검증하였다.

\section{MTMD의 이론적 해석 및 적용}

\subsection{TMD의 수학적 모델링}

감쇠가 존재하는 주시스템과 흡진기 시스템으로 구성된 TMD를 Fig. 2에 나타내었으며 이에 대한 운동방정식을 식 (1)에 나타내었다 ${ }^{(6)}$.

$$
\begin{gathered}
{\left[\begin{array}{cc}
m & 0 \\
0 & m_{a}
\end{array}\right]\left[\begin{array}{l}
\ddot{x}(t) \\
\ddot{x}_{a}(t)
\end{array}\right]+\left[\begin{array}{cc}
c+c_{a}-c_{a} \\
-c_{a} & c_{a}
\end{array}\right]\left[\begin{array}{c}
\dot{x}(t) \\
\dot{x}_{a}(t)
\end{array}\right]} \\
+\left[\begin{array}{cc}
k+k_{a}-k_{a} \\
-k_{a} & k_{a}
\end{array}\right]\left[\begin{array}{c}
x(t) \\
x_{a}(t)
\end{array}\right]=\left[\begin{array}{c}
F_{0} \\
0
\end{array}\right] \sin \omega t
\end{gathered}
$$

식 (1)의 운동방정식을 풀기 위해 $F_{0} \sin \omega t$ 를 $F_{0} e^{j \omega t}$ 로 가정하고, 정상상태 해를 식 (2)와 같이 가 정하였다.

$$
X(t)=X e^{j \omega t}=\left[\begin{array}{c}
X \\
X_{a}
\end{array}\right] e^{j \omega t}
$$

where, $\quad X=$ 주 장치의 진폭

$$
X_{a}=\text { 흡진기 질량의 진폭 }
$$

정상상태 해를 운동방정식에 대입하면 식 (3)과 같이 정리할 수 있다.

식 (3)으로부터 주장치의 내부 감쇠를 무시하고 무차원 비의 관점으로 정리하여 식 (4)와 같이 나타 내었다. 여기서, $\mu$ 는 흡진기의 질량과 주질량의 비 $\left(=m_{a} / m\right)$ 를 의미하며, $r$ 은 구동주파수와 주장치의 고유진동수의 비 $\left(=\omega / \omega_{P}\right), \beta$ 는 분리된 고유진동수 비 $\left(=\omega_{a} / \omega_{P}\right), \quad \zeta$ 는 흡진기 감쇠와 $2 m_{a} \omega_{P}$ 의 비 $(=$

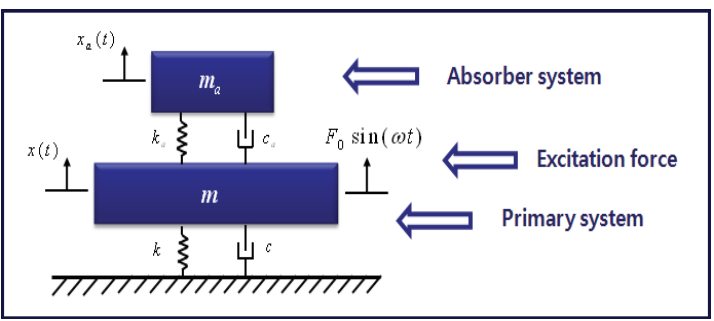

Fig. 2 Schematic showing TMD 


$$
\begin{aligned}
& {\left[\begin{array}{l}
X \\
X_{a}
\end{array}\right]=\frac{\left[\begin{array}{cc}
\left(k_{a}-m_{a} \omega^{2}\right)+C_{a} \omega j & k_{a}+C_{a} \omega j \\
k_{a}+C_{a} \omega j & \left(k+k_{a}-m \omega^{2}\right)+\left(C+C_{a}\right) \omega j
\end{array}\right]\left[\begin{array}{c}
F_{0} \\
0
\end{array}\right]}{\operatorname{det}\left(K-\omega^{2} M+\omega j C\right)}} \\
& \frac{X k}{F_{o}}=\sqrt{\frac{(2 \zeta r)^{2}+\left(r^{2}-\beta^{2}\right)^{2}}{(2 \zeta r)^{2}\left(r^{2}-1+\mu r^{2}\right)^{2}+\left[\mu r^{2} \beta^{2}-\left(r^{2}-1\right)\left(r^{2}-\beta^{2}\right)\right]^{2}}}
\end{aligned}
$$

$\left.C_{a} /\left(2 m_{a} \omega_{P}\right)\right)$ 를 의미한다.

\section{2 자기효과 감쇠}

자기효과 감쇠는 $\mathrm{ECD}$ 로, 상대적인 운동과 자기 장이 존재할 때 형성되는 와전류에 의해 감쇠력이 발생한다.

Fig. 3에서 나타낸 바와 같이, 자석과 상하진동하 고 있는 전도체가 존재할 때 전도체 내부에는 유도 전류가 발생하게 되며 이는 식(1)의 패러데이 법칙 (Faraday's law)에 의해 설명되어질 수 있다. 이렇게 발생한 유도전류는 다시 자기장과의 관계에 의해

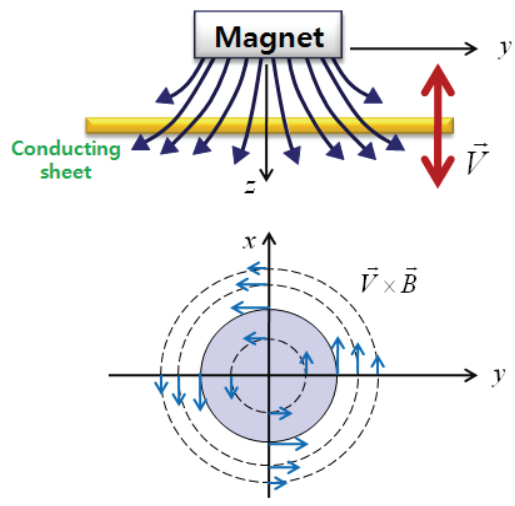

Fig. 3 Model of magnetic effect

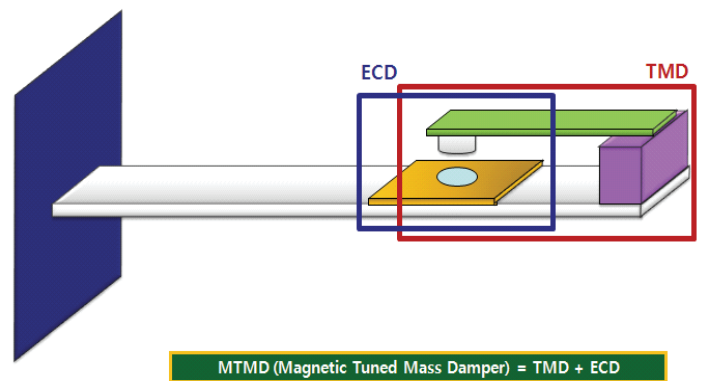

Fig. 4 Schematic showing MTMD
자석과 전도체의 상대운동의 반대되는 방향으로 반 발력이 발생하게 되며 이는 식(2)의 로렌츠 법칙 (Lorentz law)에 의해 설명되어질 수 있다. 이러한 유도전류는 전도체의 전기저항(electrical resistance) 에 의해 열로 사라지게 되고 반발력 또한 사라지게 된다. 자석과 전도체 간의 상대적인 운동이 반복적 으로 일어날 때 반발력은 생성과 소산을 반복하게 되고, 이 힘은 자석과 전도체간의 상대속도에 비례 한다 ${ }^{(2 \sim 4)}$. 따라서, 점성감쇠외 같은 역할을 하며, 식 (1)의 $C_{a}$ 가 와전류 감쇠항으로 표현된다.

\section{3 자기효과 감쇠를 갖는 $\mathrm{TMD}$ 의 외팔보 적용}

이 연구에서 제안한 자기효과 감쇠를 갖는 TMD 를 외팔보에 적용한 모습을 Fig. 4에 나타내었다. 외 팔보에 추가적인 구조물을 부착시킴으로써 $\mathrm{TMD}$ 를 구성하였으며, $\mathrm{TMD}$ 의 집중질량으로 영구자석을 사 용하고 전도체를 자석의 자기장 영향이 미치는 부 분에 부착함으로써 $\mathrm{ECD}$ 를 구성하였다. 이는 $\mathrm{TMD}$ 의 경우 어느 특정한 주파수에 대해서는 진동을 흡수하 는 성능이 뛰어나지만, 그 이외의 다른 주파수에 대 해서는 성능이 감소하는 문제가 있으며 이러한 진동 흡수성능을 향상시키기 위해 감쇠를 더하는 방안으 로 자기효과에 의한 감쇠를 적용하기 위함이다.

\section{3. 설계 및 실험}

\section{1 설계 변수 선정}

$\mathrm{TMD}$ 를 설계하기 위해 $\mathrm{TMD}$ 수학적 모델링으로 부터 구한 주구조물의 정규화된 진폭의 식을 이용 하여 각 파라미터를 선정하였다. 우선적으로 구조물 의 구조감쇠를 고려하여 구조 감쇠비 $\zeta$ 를 0.01 로 선정하였다. 흡진기의 질량과 주질량의 비는 클수록 주질량에 가해지는 진동을 흡진기의 질량이 보다 쉽게 흡수한다. 그러나 전체적인 시스템의 질량이 
늘어나므로 $\mu$ 값을 정하는 데에 한계가 있다. 따라 서 대략적으로 0.05 에서 0.25 사이의 값을 택하며 이 연구에서는 $\mu$ 를 0.25 로 선정하였다. 이렇게 해 서 정해진 $\mu(=0.25), \zeta(=0.01)$ 을 이용하여 $\beta$ 와 $r$ 의 변화에 따른 주구조물의 정규화된 진폭 결과를 얻 었으며 Fig. 5와 Fig. 6에 그 결과를 나타내었다. 이 러한 결과로부터 $\beta$ 가 0.85 일 때 가장 낮은 진폭을 지니는 것을 알 수 있었으며, 이 결과에 따라 $\beta$ 값 을 0.85 로 선정하였다.

\section{2 각 구조물 선정 및 검증}

앞서 결정된 $\mathrm{TMD}$ 의 설계변수들을 바탕으로 실 험에 용이한 크기로 각 구조물들을 선정하였으며, 이에 대한 크기 및 특성을 Table 1에 나타내었다.

결정된 설계 변수인 $\mu=0.25, \beta=0.85$ 에 근접하도록 Ansys 모달 해석을 통해 각 구조물들의 재질과 크기 를 결정하였으며, 해석 결과를 검증하기 위해서 실험 을 구성하였다. 이에 대한 Ansys 해석 결과와 실험 구성을 주구조물에 대해서는 Fig. 7에 나타내었으며, 부가구조물에 대해서는 Fig. 8에 나타내었다.

Table 1 Each part's characteristics

\begin{tabular}{c|c}
\hline \hline Parameter & Value $(\mathrm{mm})$ \\
\hline Original part's dimension $(\mathrm{mm})$ & $400 \times 30 \times 2$ \\
\hline Original part's mass $(\mathrm{g})$ & 65.28 \\
\hline Additive part's dimension(mm) & $100 \times 15 \times 0.5$ \\
\hline Additive part's mass $(\mathrm{g})$ & 18 \\
\hline Connector's mass $(\mathrm{g})$ & 5.8 \\
\hline Material & Aluminum 60 type
\end{tabular}

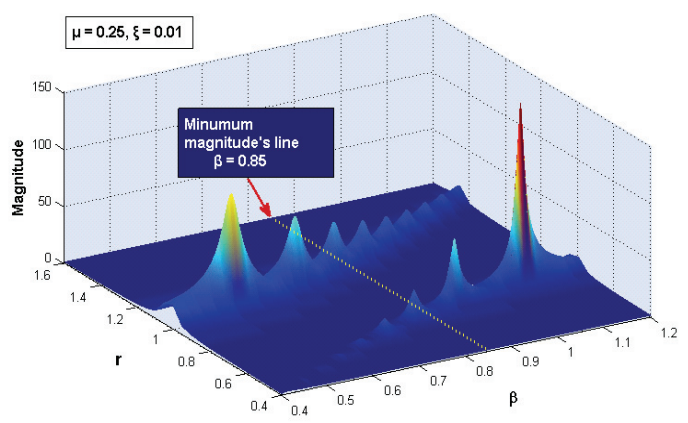

Fig. $5 \mu=0.25, \zeta=0.01$, normalized magnitude of the primary structure_3D

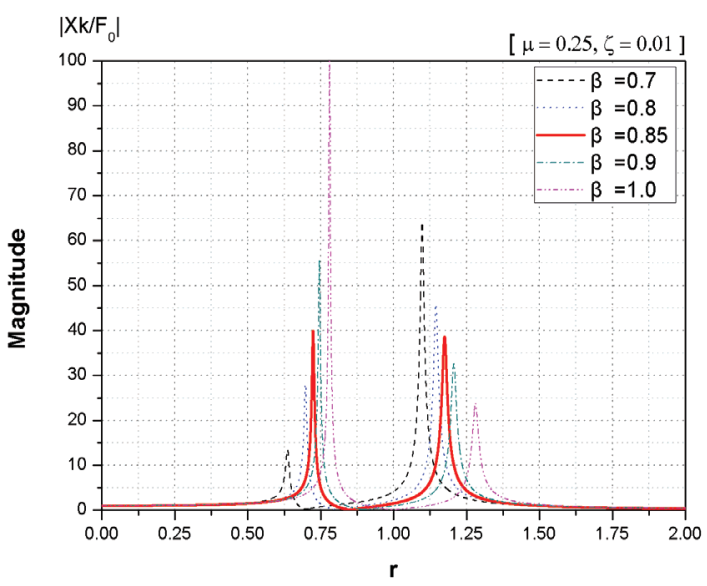

Fig. $6 \mu=0.25, \zeta=0.01$, normalized magnitude of the main structure $2 \mathrm{D}$
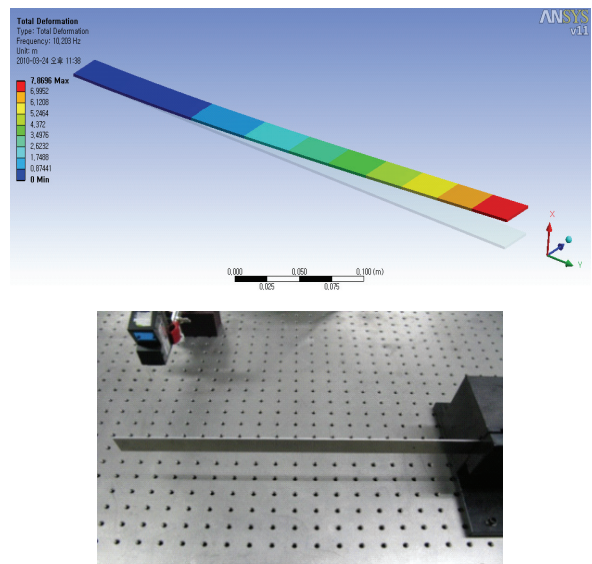

(a) Original part(1st natural frequency $=10.2 \mathrm{~Hz}$ )
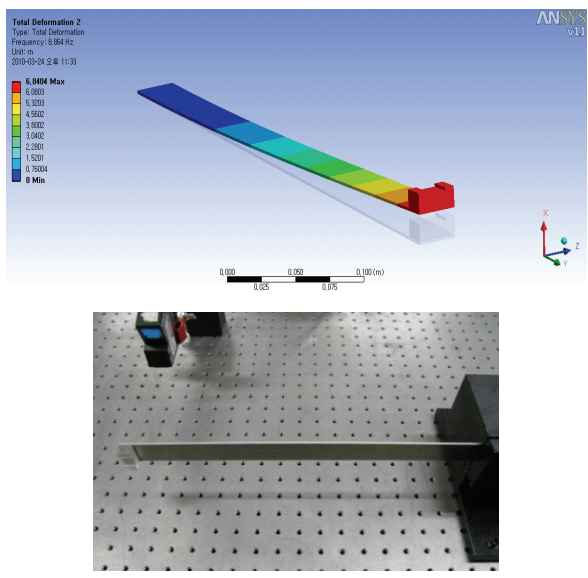

(b) Primary part(1st natural frequency $=8.86 \mathrm{~Hz}$ )

Fig. 7 Ansys sim. and experiment setup of the main parts 
Impact 해머를 이용하여 가진 후 끝단에서의 변 위 응답을 $\mathrm{FRF}$ (frequency response function) 분석 하여 Fig. 9에 나타내었다. 그 결과, Ansys 해석 결 과와 유사한 1 차 모드 고유진동수를 갖는 것을 확 인 할 수 있다. 질량비 $\mu$ 는 0.2532 이고, 분리된 고 유진동수의 비 $\beta$ 는 0.8295 이다. $\mu$ 와 $\beta$ 의 설계값과 의 차이는 설계/제작 및 실험상에 발생하는 오차이 며, 이 연구에서는 $\mu=0.25, \beta=0.85$ 의 값을 사용하 였다.

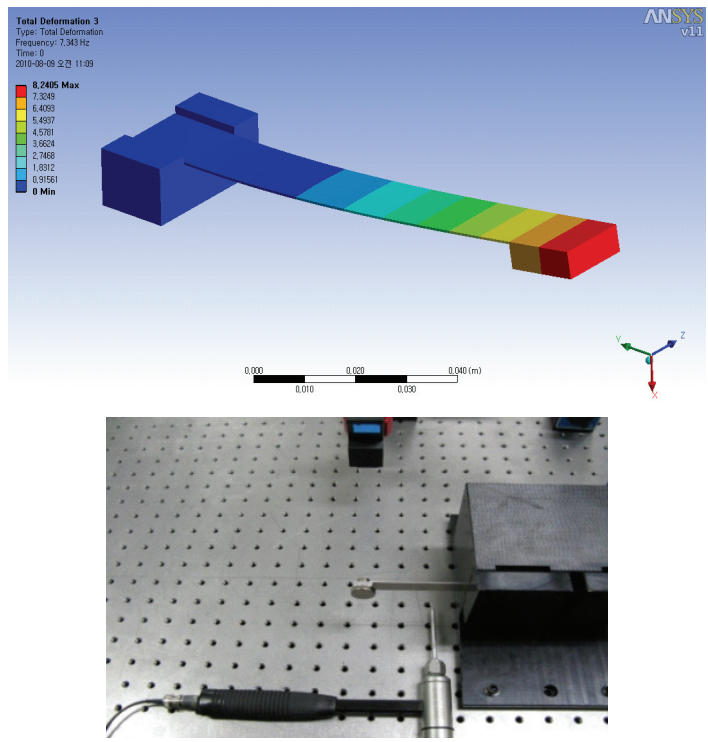

Additive part $(1$ st natural frequency $=7.34 \mathrm{~Hz}$ )

Fig. 8 Ansys sim. and experiment setup of the addtive parts

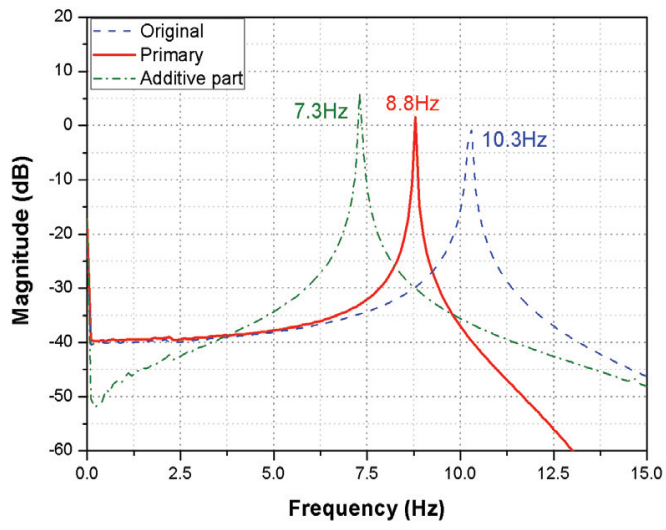

Fig. 9 The FRF results of the experiment about the each parts

\section{3 실험 구성}

압전재료를 이용하여 가진 실험을 하기 위한 구 성도를 Fig. 10 에 나타내었다.

실제 실험 구성은 Fig. 11에 나타내었으며, 컨트 롤러(controller)로는 dSPACE 사의 1103 controller board를 사용하였다. 이를 MATLAB/Simulink와 연 동하여 sine sweep 신호를 고전압 앰프를 거쳐 압 전재료에 인가하였으며, 외팔보 끝단에서의 변위 응 답을 레이저 센서를 이용하여 얻었다. 식 (7)에 압전 재료의 인가전압에 대한 가진력 식을 나타내었으며, 압전 가진력에 사용된 변수는 다음과 같다. $L_{P Z T}$ 는 압전재료의 길이, $L_{F}$ 는 외팔보의 고정단으로부터 가진력이 가해지는 위치, $d_{31}$ 압전 변형 계수, $E_{a}$ 는 압전재료의 강성 계수, $\mathrm{b}$ 는 외팔보의 폭, $t_{a}$ 는 압전 재료의 두께, $t_{c}$ 는 외팔보의 두께, $V(t)$ 는 인가 전 압이다. 또한, Table 2에서 압전재료의 가진력 식을 구하기 위한 변수 값들을 나타내었다. 이로부터 얻 은 진폭 $2 \mathrm{~V}$ 의 sine sweep 신호를 인가할 때의 가 해지는 가진력을 Fig. 12에 나타내었다.

$$
F(t)=\frac{L_{P Z T}}{2 L_{F}} d_{31} E_{a} b\left(t_{a}+t_{c}\right) V(t)
$$

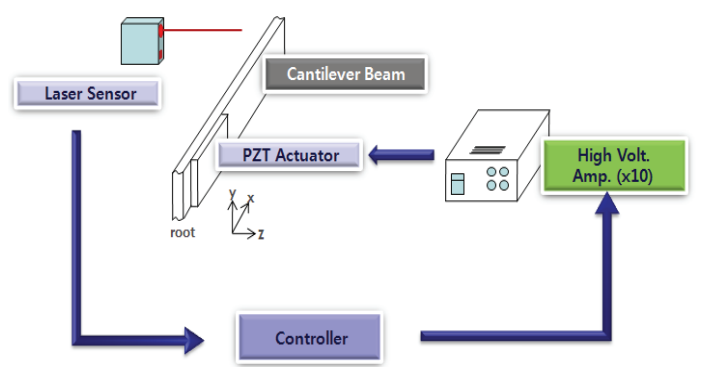

Fig. 10 Schematic showing experiment setup

Table 2 The parameters of the excitation force's equation about the piezo material

\begin{tabular}{c|c}
\hline \hline Parameter & Value $(\mathrm{mm})$ \\
\hline Piezo material's dimension $(\mathrm{mm})$ & $30 \times 10 \times 0.5$ \\
\hline $\begin{array}{c}\text { Piezoelectric strain coefficient } \\
{\left[d_{31}\right](\mathrm{m} / \mathrm{V})}\end{array}$ & $-210 \times 10^{-12}$ \\
\hline Stiffness coefficient & 100 \\
\hline $\begin{array}{c}\text { The excitation position from the root } \\
\text { of a cantilever beam }(\mathrm{mm})\end{array}$ & 42.5 \\
\hline The thickness of a cantilever beam $(\mathrm{mm})$ & 2 \\
\hline
\end{tabular}




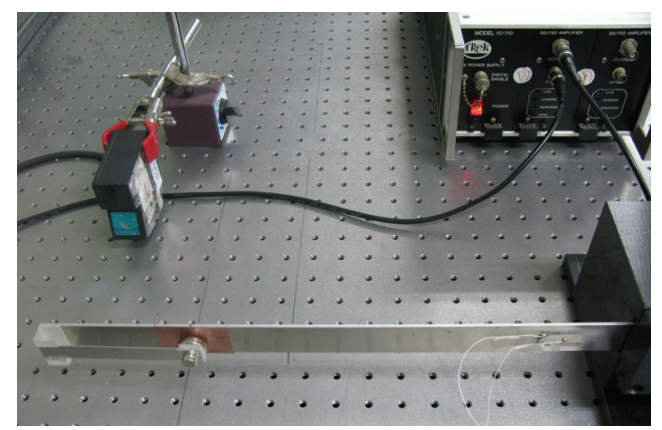

Fig. 11 Experiment setup

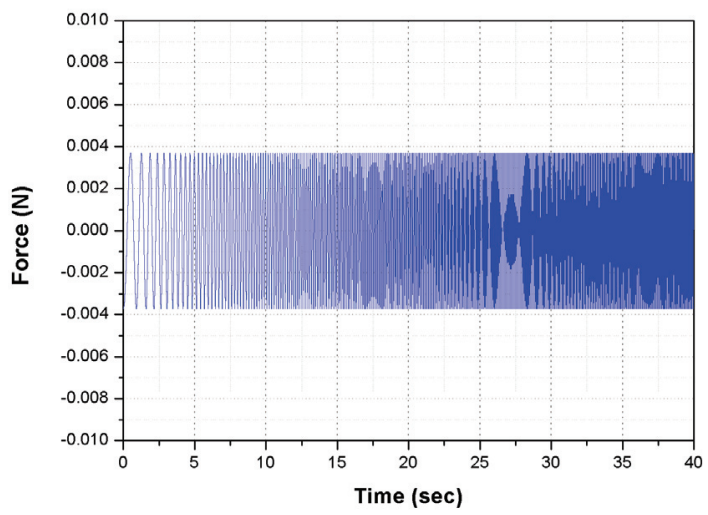

Fig. 12 Sine-sweep excitation force by the piezo

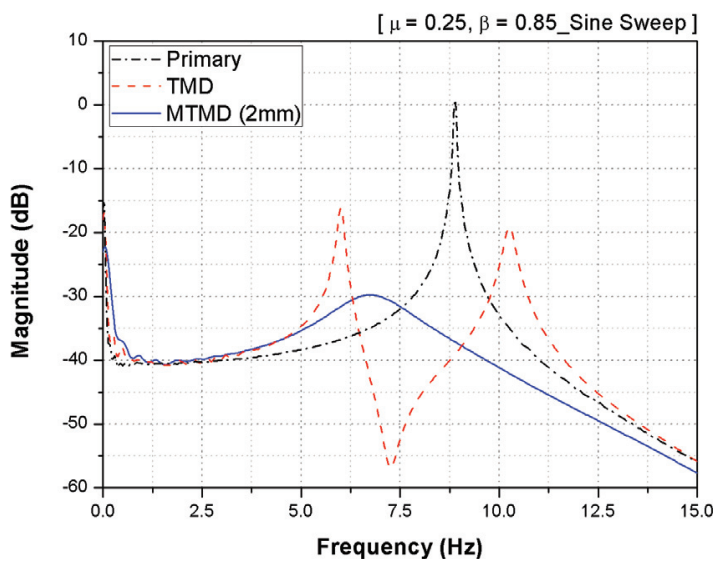

Fig. 13 The FRF results of MTMD

Fig. 13에 실험의 FRF 결과를 나타내었으며, 이 결과로부터 $\mathrm{TMD}$ 의 진동 흡수 성능이 기존 외팔보만 존재하는 경우보다 진폭이 줄어듬을 알 수 있으며 어느 특정한 주파수 구간에 대해 매우 우수함을 알 수 있다. 반면에 그 특정한 주파수를 중심으로 진동

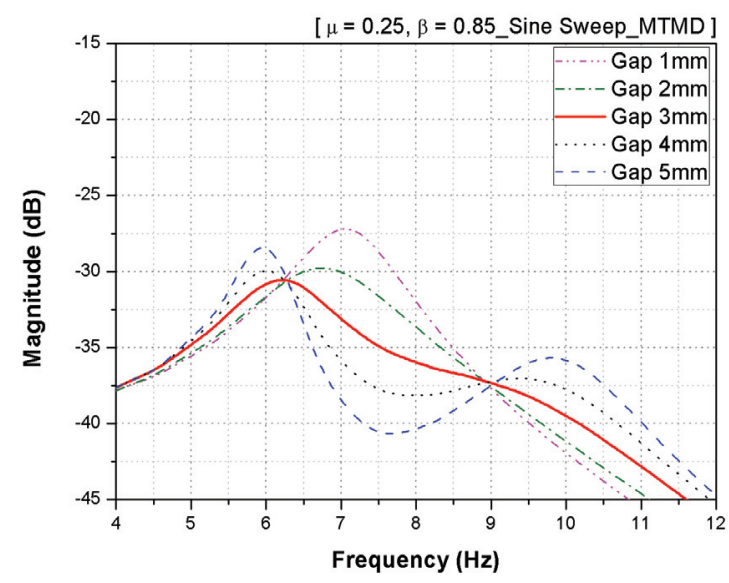

Fig. 14 The FRF results of MTMD about gap change

흡수성능이 크게 감소함을 확인할 수 있다. 따라서 이러한 문제점을 해결하기 위해 제안된 $\mathrm{MTMD}$ 의 결 과를 보았을 때, $\mathrm{TMD}$ 에서 발생 가능한 최대 진폭이 크게 줄었음을 확인할 수 있으며, 이로부터 특정 주 파수를 중심으로 진동흡수성능이 감소하는 $\mathrm{TMD}$ 의 문제를 $\mathrm{MTMD}$ 를 적용함으로써 충분히 해결할 수 있음을 알 수 있다. Fig. 14에서는 MTMD의 자석과 전도체 간의 간격변화를 주어 실험한 결과로 최적 의 진동흡수성능을 지니는 간격이 존재함을 확인할 수 있으며, 이러한 간격 변화는 자기효과 감쇠의 변 화이다. 따라서, 간격변화로 인한 자기효과 감쇠의 변화 및 진동성능에 미치는 영향에 대한 추가적인 연구가 필요하다.

\section{4. 결 론}

이 연구에서는 자기효과 감쇠를 갖는 $\mathrm{TMD}$ 인 $\mathrm{MTMD}$ 를 이용하여 외팔보의 수동형 진동제어를 수행하였다. TMD의 경우 특정한 주파수에 대해서 는 진동을 흡수하는 성능이 뛰어나지만, 이를 중심 으로 근접한 주파수에서 진동흡수성능이 감소하는 문제가 있다. 이는 흡진기에 감쇠를 더함으로써 해 결할 수 있으며, 이러한 감쇠를 추가하는 방안으로 자기효과 감쇠를 적용하였다. 우선적으로, $\mathrm{TMD}$ 에 대한 수학적 모델링을 통해 우수한 성능을 갖도록 각 설계 변수들을 추정하였으며, 기본적인 외팔보에 이를 적용하여 설계를 수행하였다. 이러한 설계를 통해 구성된 $\mathrm{TMD}$ 에 대해 실험과 Ansys 해석을 수 
행하여, 두 결과를 비교함으로써 실험 결과를 검증 하였다. 이러한 $\mathrm{TMD}$ 에 대한 결과를 통해, $\mathrm{TMD}$ 의 진동흡수특성인 특정 주파수를 중심으로 근접한 주 파수에서 진동흡수성능이 감소하는 문제를 확인하 였다. 따라서 $\mathrm{TMD}$ 의 진동흡수성능을 개선시키기 위해, 이 연구에서 제안한 자기효과 감쇠를 적용한 $\mathrm{TMD}$ 인 $\mathrm{MTMD}$ 를 구성하였으며, 이에 대한 실험을 수행함으로써 $\mathrm{MTMD}$ 가 기존 $\mathrm{TMD}$ 의 진동흡수성능 을 향상시키는 데, 매우 효과적임을 검증하였다. 마 지막으로 자석 간격의 변화에 따른 진동억제 성능 의 변화가 있었으며, 자기감쇠 효과 및 감쇠증가에 따른 진동억제 성능 변화에 대한 연구가 추가적으 로 수행되어야 한다.

\section{후 기}

이 연구는 (주)현대위아의 포신진동 저감기법 연 구 및 한국항공우주연구원의 연구비 지원에 의해 수행되었으며, 이에 관계자 여러분께 감사드립니다.

\section{참 고 문 헌}

(1) Inman, D. J., 2000, Engineering Vibration.
(2) Kwak, M. K., Lee, M. I. and Heo, S., 2003, Vibration Suppression Using Eddy Current Damper, Transactions of the Korean Society for Noise and Vibration Engineering, Vol. 13, No. 10, pp. 760 766.

(3) Bae, J. S., Kwak, M. K. and Inman, D. J., 2005, Vibration Suppression of Cantilever Beam Using Eddy Current Damper, Journal of Sound and Vibration, Vol. 284, pp. 805 824.

(4) Sodano, H. A., Bae, J. S., Inman, D. J. and Belvin, W. K., 2005, Concept and Model of Eddy Current Damper for Vibration Suppression of a Beam, Journal of Sound and Vibration, Vol. 288, pp. 1177 1196.

(5) Sodano, H. A., Bae, J. S., Inman, D. J. and Belvin, W. K., 2006, Improved Concept and Model of Eddy Current Damper, ASME Journal of Vibration and Acoustics, Vol. 128, pp. 295 302.

(6) Kwag, D.-G., Bae, J.-S., Hwang, J.-H. and Kim, H.-S., 2011, A Study on the Vibration Damping of a Barrel Using Vibration Absorber, Transactions of the Korean Society for Noise and Vibration Engineering, Vol. 21, No. 5, pp. 408 415. 